\title{
Challenges of tuberculosis management in high and low prevalence countries in a mobile world
}

\author{
*Chris Griffiths', Monica Barne'2, Puneet Saxena ${ }^{3}$, John Yaphe ${ }^{4}$ \\ ${ }^{1}$ Professor of Primary Care, Centre for Primary Care and Public Health, Blizard Institute, Queen Mary University of London, London, UK \\ ${ }^{2}$ Head, Training Programmes Division, Chest Research Foundation, Pune, India \\ ${ }^{3}$ Reader, Department of Internal Medicine, Armed Forces Medical College, Pune, India \\ ${ }^{4}$ Life and Health Sciences Research Institute (ICVS), School of Health Sciences, University of Minho, Braga and ICVS-3Bs, PT Government \\ Associate Laboratory, Braga, Guimarães, Portugal
}

\section{Introduction}

In this issue of the PCRJ, Bishara et al.' present a case report about the treatment of a pregnant woman with tuberculosis (TB). She had emigrated from a country with a high prevalence of TB to one with a lower prevalence. This presented a challenge to her physicians who were faced with identifying and treating close contacts who were also infected. This Perspective article explores in more depth some of the questions raised by this case report. It discusses the role of primary care physicians in low prevalence countries who can implement evidence-based screening programmes, it discusses effective strategies for the diagnosis and treatment of TB in countries with high TB prevalence, and it presents insights from medical anthropology that can help practitioners overcome the barriers to TB diagnosis, treatment and screening described in the case report.

\section{Screening and management of tuberculosis in immigrants}

The case report from Bishara et al. ${ }^{1}$ of active TB occurring in four members of a family recently migrated from Ethiopia to Israel provides an excellent basis for considering how primary care can contribute to early diagnosis and treatment of TB. The authors provide a thorough assessment of the barriers that led to delay in diagnosis in all four family members, and a clear description of the challenges of appropriate management. One aspect not addressed, and which potentially could have had a key influence on the evolution of the disease in all four cases, is the impact of screening for TB - and other infectious diseases - in primary care.

\section{Health of migrants}

Migrants make up an increasing proportion of European populations. ${ }^{2}$ Migrants often have complex health care needs, being at increased risk of communicable and non-communicable disease, as well as social and psychological problems, sometimes arising from trauma experienced in their countries of origin. Good health care for migrants is therefore an important area, but one which is frequently marginalised through political controversy in a time of scarce health care resources.
The family in the case report have recently migrated from Ethiopia, a country afflicted by rates of both TB and Human Immunodeficiency Virus (HIV) that are amongst the highest in the world (TB incidence: 247/100,000 population; ${ }^{3}$ HIV prevalence $1.4 \%$ in the adult population ${ }^{4}$ ). The family must therefore be considered at increased risk of these infections.

Most cases of active TB in the UK arise after migration from reactivation of latent disease, rather than being acquired by new cross infection. ${ }^{5}$ Thus, screening for active disease in the country of origin or at the port of entry for active disease is relatively ineffective. What triggers reactivation of disease after migration is unclear, but potentially reflects influences including the development of vitamin $D$ deficiency or ill-defined effects of stress on the immune system.

\section{Guidelines on screening for TB and HIV}

UK guidelines recommend screening migrants for both TB and HIV in primary care. ${ }^{6 \cdot 8}$

For new entrants from countries with a high incidence of $T B$, the UK National Institute for Health and Care Excellence (NICE) recommends: ${ }^{6}$

- For children under 5 years, offer a Mantoux (tuberculin) skin test. If strongly positive, refer to consider treating latent TB.

- For children aged 5-15 years, offer a Mantoux test. If positive, follow with an Interferon Gamma Release Assay (IGRA).

- For people aged 16-35 years, offer either an IGRA alone or a dual strategy (Mantoux test followed by IGRA).

- For people over 35 years, consider the individual risks and benefits of likely subsequent treatment before offering testing.

For HIV, NICE recommends that:

'All health professionals should routinely offer and recommend an HIV test to men and women known to be from a country of high HIV prevalence. ${ }^{77}$

How effective is screening and what evidence supports these recommendations?

a) Screening for TB in primary care is effective and acceptable

In a cluster randomised trial of 50 general practices, set in inner

\footnotetext{
* Correspondence: Professor Chris Griffiths, Centre for Primary Care and Public Health, Blizard Institute, Queen Mary University of London, E1 2AB, UK. E-mail: c.j.griffiths@qmul.ac.uk
} 
London, practices trained to screen people registering in primary care for TB significantly increased the proportion of cases of TB diagnosed in primary care. ${ }^{9}$ Screening was acceptable to migrants ${ }^{10}$ and was probably cost-effective. ${ }^{11}$ Screening consisted of a short set of questions on symptoms of active TB, followed by a tuberculin skin test and if indicated, a chest X-ray and sputum samples for microscopy and culture for acid fast bacilli. Since 2007, general practices in Hackney, east London have routinely offered TB screening to new entrants when they register in primary care. During this period incidence of TB has halved in the borough.

\section{b) Interferon gamma release assays are a useful screening test for TB in primary care}

Drawbacks of the traditional tuberculin skin test for TB include poor sensitivity and specificity (especially in people immunised with BCG), and the need for the patient to return to have their test read. Interferon gamma release assays (IGRA) overcome both of these problems. They work on the principle that white blood cells (Tlymphocytes) of a person infected with TB will release interferon gamma when stimulated by antigens unique to Mycobacterium tuberculosis (CFP-10 and ESAT-6). Neither the BCG bacillus nor nonmycobacterial TB have these antigens. The place of IGRA testing is evolving, but studies of serology testing of migrants in primary care show that it is probably a cost-effective way of screening for latent TB infection. ${ }^{12}$ A further advantage is that the blood drawn can also be tested for other infections, such as HIV and hepatitis. Modelling suggests that screening with IGRA could replace screening at port of entry with chest radiography. ${ }^{12}$

\section{c) Screening for HIV in primary care is effective and acceptable}

Results of a recent cluster randomised trial of 40 practices in east London show that training practices to screen new registrants for HIV using a point-of-care rapid HIV test leads to increased and earlier detection of HIV. ${ }^{13} \mathrm{~A}$ majority of the new cases of HIV found in this study were in black Africans, highlighting the ability of a primary care-based approach to reach an important at-risk group. This study is the first randomised study to test the impact of screening for HIV and lends support for NICE recommendations on HIV testing.

More importantly, these studies show that primary care can play a critical role in screening migrants for infectious disease. On the basis of these studies, primary care in some east London boroughs is adopting a model of screening by serology or rapid point-of-care testing for multiple infectious diseases in migrants registering in primary care. Screening is supported by locally agreed incentive programmes.

\section{Implications for this case report}

Potentially therefore, the family featured in the case report by Bishara et al. could have been screened for TB, HIV and other infectious diseases such as hepatitis when they registered in primary care. It is possible that they could have been screened at an asymptomatic stage when the entire family may have had latent, rather than active TB. Positive results of screening would have triggered referral for further assessment by the local specialist TB team. It is likely they would have been offered chemoprophylaxis to prevent reactivation of TB. Early identification of latent TB infection in these family members could have prevented reactivation to active disease and - in the case of those members with pulmonary TB (the mother and children) - potential further transmission to others. Clearly these benefits would only be possible if migrants are able, and indeed encouraged, to register in primary care. The public health implications of effective screening of migrants both for migrants themselves and wider society are obvious. Any measures that restrict access to health care for migrants are to be resisted.

\section{Diagnosis and treatment of tuberculosis in low-income countries}

According to the 2012 World Health Organization report, TB is now a major health problem worldwide with a global incidence of 8.6 million and mortality of 1.3 million. ${ }^{14}$ With most cases occurring in Asia (58\%) and Africa (27\%), TB seems to be a disease of the underprivileged, resource-limited developing nations. Factors explicitly linked with poverty such as malnutrition, overcrowding, poor healthcare infrastructure and a higher number of people living with HIV (PLHIV) are all responsible for the increased burden of TB in the developing world. ${ }^{15,16}$

Diagnosis of TB is a challenge due to the long latent period, outreach to almost every organ of the body, and varied presentations. Timely detection of pulmonary TB cases, which constitute about $85 \%$ of all TB cases, is especially important since they contribute to the chain of transmission in the community. ${ }^{14}$ In a high-burden country, the index of suspicion should be high but rational. Any patient with signs and symptoms suggestive of TB should be called as 'Presumptive TB' (earlier labeled as TB suspect) and should be evaluated ${ }^{17}$ (see Figure 1).

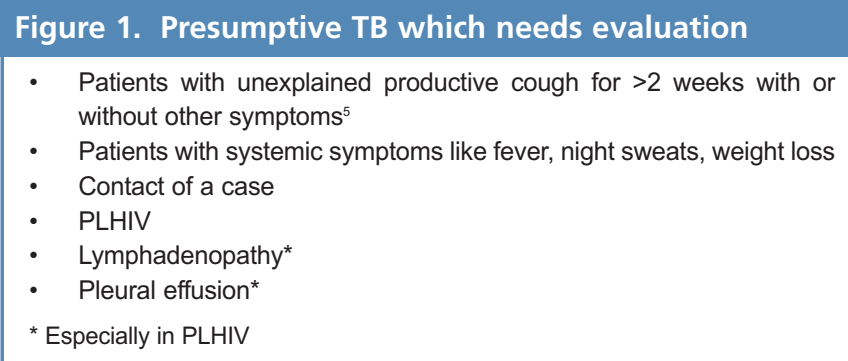

Amongst the four diagnostic arms of TB - clinical, microbiological, pathological and radiological - microbiological diagnosis is the most specific and reliable and all efforts must be made to establish a microbiological diagnosis. Serodiagnosis may be used as a screening tool in developed countries, but in a resourcelimited setting these inaccurate and imprecise tests merely add to the cost of the country's TB control programmes and hence are not recommended by $\mathrm{WHO}^{18,19}$ (see Figure 2).

\section{Important points to note about the diagnostic algorithm}

- When sputum is not easily obtainable, use induced sputum or gastric aspirates (especially in children) or bronchoscopic lavage where available..$^{23,24}$

- Sputum processing methods involving bleach digestion, centrifugation or gravity sedimentation may be employed. ${ }^{21,25-27}$ 
Figure 2. Diagnostic algorithm for pulmonary tuberculosis..$^{20}$ As used in India and endorsed by Central TB Division, Directorate General of Health Services, Ministry of Health and Family Welfare, Government of India

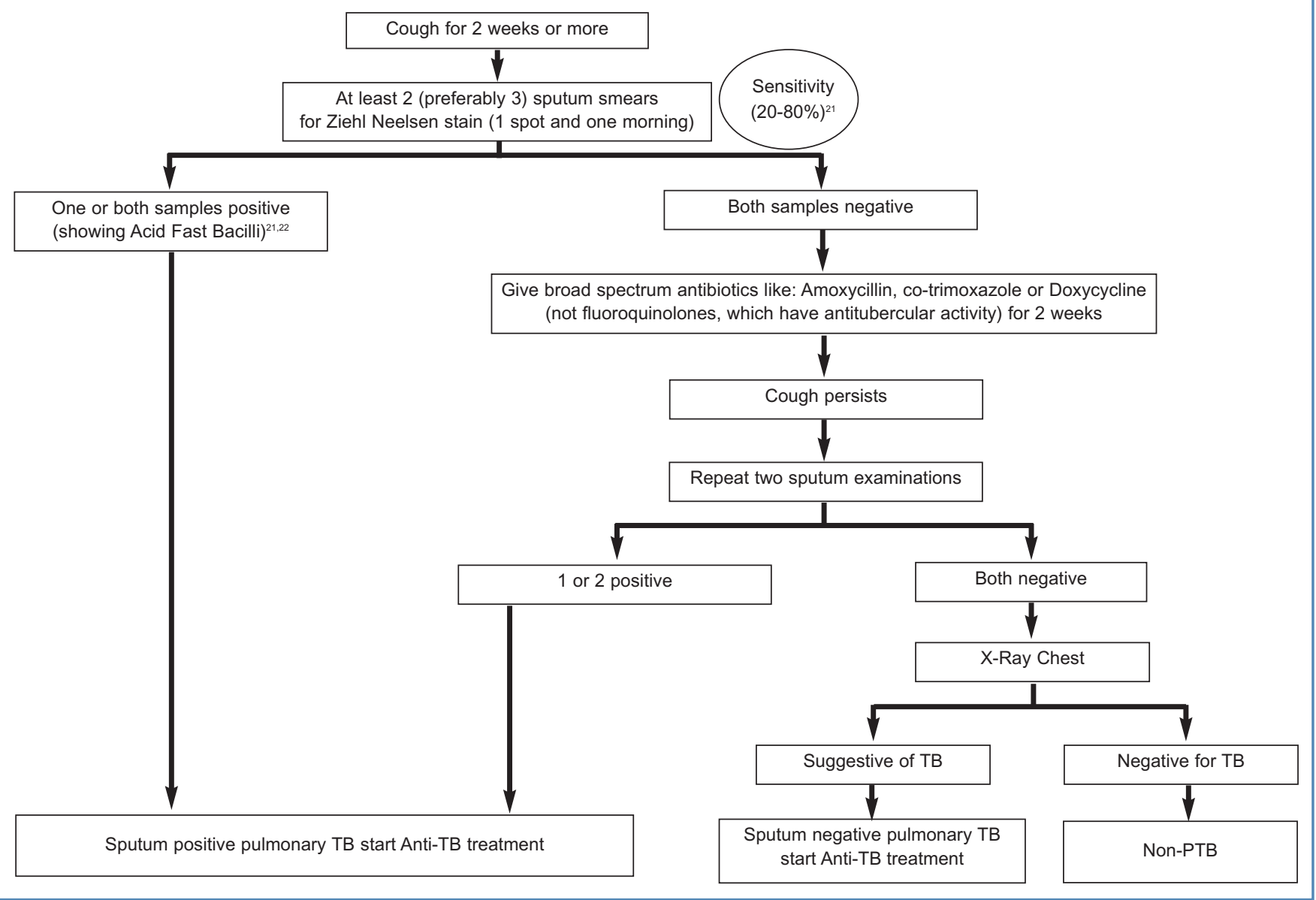

- LED microscopy, which is more sensitive than conventional ZN microscopy and has qualitative, operational and cost advantages over both conventional fluorescence and ZN microscopy, may be utilised where feasible. $21,26,28$

- In cases of pauci-bacillary TB, children and PLHIV, solid or liquid cultures or molecular tests may be done. Rapid molecular tests like GenoType ${ }^{\circledast}$ MTBDRplus and Xpert ${ }^{\circledast}$ MTB/RIF have now been endorsed by WHO based on emerging evidence.

- Chest X-ray (CXR) is a sensitive but nonspecific test to detect TB with $10-15 \%$ under-reading and about $40 \%$ over-reading. ${ }^{25}$ However, when the pre-test probability is high and in PLHIV, CXR may be ordered up-front if the initial smears are negative. ${ }^{29} \mathrm{Few}$ cases may require a CT scan for confirmation.

Extra-pulmonary tuberculosis When extra-pulmonary TB is suspected, appropriate specimen(s) from the affected site should be obtained and examined microbiologically, followed by microscopy or culture. Most such cases are pauci-bacillary, hence imaging modalities, cytology and histopathology are often required. Adenosine deaminase levels in body fluids are a useful adjunct in these cases but are not very specific. All these cases must be evaluated for concurrent pulmonary $T B$, especially in the presence of cough. ${ }^{22,25}$

Categorisation of patients Based on the above, patients are categorised as a "bacteriologically-confirmed" or as a "clinically diagnosed" case depending on whether microbiological confirmation with microscopy, culture or molecular methods is available or not. ${ }^{4}$ Meticulous follow-up and reconsideration of diagnosis should be done for the latter case should such evidence appear in due course. Cases are also classified depending on the anatomical site of disease, history of previous treatment (relapse, failure, or lost to follow-up), drug resistance (if known) and HIV status.

\section{Treatment}

New cases All new cases are recommended to take 6 months treatment:

- Intensive phase: 2 months of isoniazid(H), rifampicin(R), pyrazinamide(Z) and ethambutol(E)

- Continuation phase: 4 months of HR

In populations where prevalent isoniazid resistance is high (based on surveillance studies), ethambutol may be added to HR in the continuation phase.

Drug dosages should be based on the patient's weight as advocated by WHO. ${ }^{22}$

Retreatment cases Patients who have received at least one month's treatment in the past and who present again with active disease either because of treatment failure, relapse or they were lost to follow-up - represent an important group since around 20\% of 
Figure 3. Algorithm for management of retreatment cases. Adapted from: World Health Organization. Treatment of tuberculosis guidelines. 4th Edition, 2010, Pg 38-39

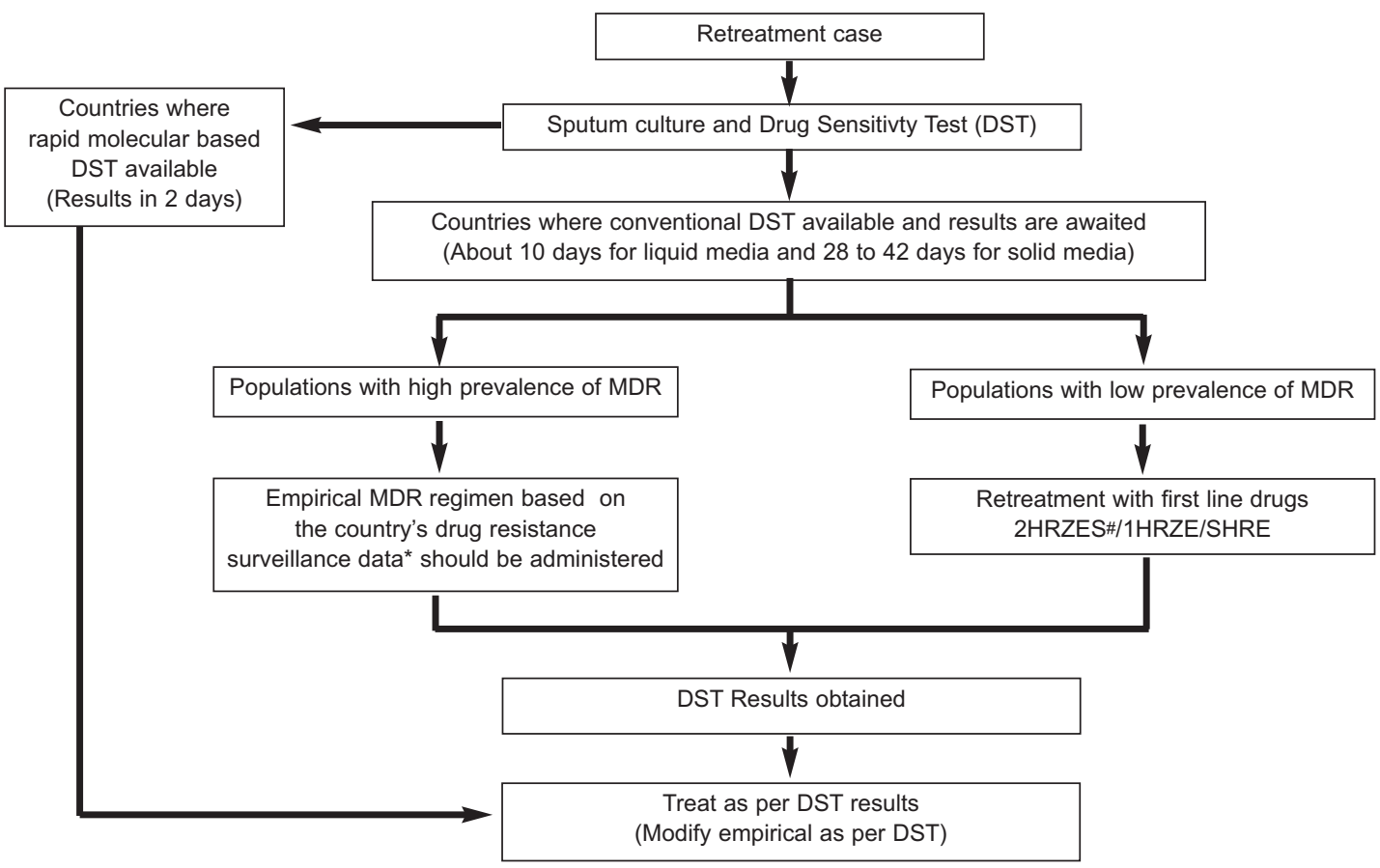

*Guidance on designing a country's standard MDR regimen is provided in Chapter 7, Reference 22 \#S-Streptomycin

them may have Multi Drug Resistant TB (MDR TB) ${ }^{14}$ - see Figure 3.

It is most important for all National Tuberculosis Programmes (NTPs) that countries have their own nation-specific guidelines to define MDR suspects, and management of retreatment cases should be based on surveillance data, resource availability, laboratory infrastructure and other population-specific issues.

"Failure" cases are more likely to have MDR than the other two retreatment categories and some countries may adopt a "mixed" approach. $^{22}$

Frequency of treatment There is increasing evidence to advocate daily dosing schedules to reduce the risk of treatment failure, relapse and acquired drug resistance. ${ }^{30,31}$ WHO recommends that the optimal dosing frequency is daily. However, for convenience of implementation, thrice-weekly treatment is acceptable during the continuation phase only if every dose is directly observed (termed 'Directly Observed Treatment' or DOTS). Directly observed, thriceweekly therapy throughout treatment is acceptable if HIV infection is ruled out. ${ }^{22}$

Follow-up Repeat sputum examination at the end of the intensive phase and at the end of treatment is required. Repeat sputum evaluation during the middle of the continuation phase is no longer recommended. ${ }^{22,32}$ Any sputum positivity during follow-up makes the patient an MDR suspect and NTPs may advocate culture/DST. Readers are referred to comprehensive guidelines available for the management of MDR TB. ${ }^{33,34}$

\section{Conclusion}

TB has now re-emerged as a major health hazard, and resourcelimited countries need to build up robust National Tuberculosis
Programmes (NTPs) based on epidemiological and clinical evidence to overcome the socio-cultural and economic limitations of the country. Apart from trying to upgrade the diagnostic and therapeutic facilities of the country, the NTPs should also aim at educating health care providers at all levels, increasing public awareness, promoting lifestyle improvement and cough etiquettes in the community. Progressively moving towards universal access to healthcare, adherence to guidelines, and changing attitudes, it is a realistic optimism that the next generation may live in a TB-free world.

\section{Why the anthropological approach is valuable to family doctors treating patients with tuberculosis from different cultures}

The article by Bishara et al. ${ }^{1}$ in this issue is instructive for many reasons. TB remains an important public health problem in many parts of the world, including Portugal. There were 2500 new cases reported in Portugal in 2009, giving an annual incidence of 24 per $100,000 .{ }^{35}$ Maintaining a high index of suspicion and remaining vigilant in finding close contacts at risk for infection is a constant challenge. TB in pregnancy is also a diagnostic and therapeutic challenge that requires clinical expertise. ${ }^{36}$ But the added value of this case report lies in the cross-cultural lessons that it can teach us.

The arrival of Jewish immigrants from Ethiopia to Israel in two large waves in the 1980s and 1990s presented a significant challenge to Israeli society and the healthcare system. ${ }^{37}$ Infectious diseases including malaria, TB and intestinal parasites presented challenges to clinicians who were unfamiliar with these conditions. ${ }^{38}$ 
More important, patients speaking a different language coming from an African agrarian society and arriving in a post-industrial Western society with very different values from those of the host culture experienced a profound sense of culture shock. This resulted in depression, suicides and other forms of social disruption. ${ }^{39}$ The healthcare system required different tools to cope with this.

Help was available in the form of medical anthropology. The work of Arthur Kleinman, ${ }^{40}$ Cecil Helman ${ }^{41}$ and others has direct application to the work of family doctors. When a patient says, "Feed a cold and starve a fever," they are referring to widely-held health beliefs that can have significant effects on their health behaviours. If they prefer chicken soup to antibiotics for respiratory infections, this can also affect outcomes. Culturally-bound health beliefs and practices can affect consulting rates, attendance at screening programs and treatment compliance, including completion of TB treatment. ${ }^{42}$

It has been argued that all medical encounters are cross-cultural encounters. The ability to ask the right questions respectfully, to listen attentively, to learn the cultural lessons presented, and to apply these lessons effectively in diagnosis and treatment, are the legacy of medical anthropology. This, in fact, is a definition of patient-centred care. ${ }^{43}$ Linguistic translation is not enough. Cultural interpretation is necessary in cross-cultural medicine as well. Simple questions such as, "What do you think is causing your problem?", "What do you call this in your language?", "What do you require to treat it?", "What will happen if you treat it?", "What will happen if you don't?", and "How long will this last?", are all useful in building bridges of cultural understanding about disease. All doctors learning about their patients' health belief models can apply these questions.

Fortunately, expert resources were available and were used in the successful absorption of Ethiopian immigrants to Israel. Medical anthropologists who had studied the medical culture of Ethiopia were indispensible at the beginning of this adventure. ${ }^{44}$ The language and concepts of health and disease, the use of traditional medicines and traditional healers, and the system of values related to health all needed to be explained to health professionals in the host culture. Translation was provided initially, especially for older patients who spoke little or no Hebrew. Later, because of their language acquisition skills, children became interpreters for the elders, even though this was often inappropriate in medical encounters.

As expertise and trust grew, and social barriers broke down, other techniques were employed. Long interviews and focus group methods were employed to help decipher the codes of health beliefs and behaviours. ${ }^{45}$ Parents revealed how common symptoms such as fever or anorexia were viewed as symptoms of malaria or other diseases unfamiliar to their new doctors. Other symptoms such as weight loss and difficulty feeding in the newborn child might call for traditional procedures like excision of the uvula, which were also foreign. A belief in the power of injections to heal compared to the relative inefficiency of tablets might lead to difficulties in adherence to long-term regimens such as TB treatment. Belief in the therapeutic power of blood-letting on the other hand might lead to surprising compliance with requests to appear for laboratory tests requiring venipuncture. ${ }^{46}$
The success of culture-sensitive medicine can be seen in the diagnosis, treatment and prevention of $\mathrm{TB}$ in the Ethiopian community in Israel. Although cases still appear, as this case report demonstrates, ${ }^{1}$ and constant vigilance is required among health workers caring for members of this community, this can be considered a success story. ${ }^{47}$

Other developments that are worth noting are the training of community health workers from among the immigrants themselves. The innovative Refuah Shlema program has resulted in the successful integration of motivated, idealistic members of the community into the health care team. Their credibility, respect and effectiveness among their fellow immigrants and the next generation of native born Israelis of Ethiopian origin is a remarkable achievement and an example worth copying. ${ }^{48}$ The next challenge the society faces, as infections like TB are overcome, is the growing problem of obesity and diabetes in this community. While almost unheard of in Ethiopia, this is becoming a public health problem. Acculturation has health risks as well as benefits, and unique culturally-sensitive solutions are needed to face this issue too. ${ }^{49}$

Rapid international travel and freely mobile populations draw these cross-cultural medical issues into sharp focus. Air travel was implicated in the spread of the recent SARS epidemic. Cultural issues require attention in the management of infectious and non-infectious diseases and will continue to occupy our attention in medicine.

\section{Conclusion}

Tuberculosis remains a significant public health problem in both high- and low-prevalence countries. Sharing of knowledge and experience from many settings and disciplines, as demonstrated in the case report by Bishara et al.,' and in this Perspective article, will be necessary to achieve the goal of a TB-free world.

\section{Handling editor Jaime Correia de Sousa}

Conflicts of interest The authors declare that they have no conflicts of interest in relation to this article.

Contributorship CG wrote the section on screening and management of TB in immigrants. CG is an Assistant Editor of the PCRJ, but was not involved in the editorial review of, nor the decision to publish, this article. MB and PS wrote the section on diagnosis and treatment of TB in low-income countries. JY wrote the section on the anthropological approach to family doctors treating patients with tuberculosis from different cultures.

\section{References}

1. Bishara H LM, Vinitsky O, Weiler-Ravel D. Indolent pneumonia in a pregnant, recent immigrant from Ethiopia: Think TB. Prim Care Respir J 2014;23(1):102-05. http://dx.doi.org/10.4104/pcrj.2014.00001

2. Rechel B, Mladovsky P, Ingleby D, Mackenbach JP, McKee M. Migration and health in an increasingly diverse Europe. Lancet 2013;381(9873):1235-45. http://dx.doi.org/ 10.1016/S0140-6736(12)62086-8

3. World HealthOrganisation. World Health Organization (WHO) estimates of tuberculosis incidence by rate, 2012 (sorted by rate). World Health Organisation; 2012 [cited 2014 02/02/14]; Available from: http://www.hpa.org.uk/webc/ HPAwebFile/HPAweb_C/1317140584841.

4. World Health Organisation. WHO African Region: Ethiopia statistics summary (2002 - present). 2012 [cited 2014 02/02/2014]; Available from: http://apps.who.int/gho/ data/node.country.country-ETH.

5. Maguire H, Dale JW, McHugh TD, et al. Molecular epidemiology of tuberculosis in London 1995-7 showing low rate of active transmission. Thorax 2002;57(7):61722. http://dx.doi.org/10.1136/thorax.57.7.617 
6. Abubakar I, Griffiths C, Ormerod P; Guideline Development Group. Diagnosis of active and latent tuberculosis: summary of NICE guidance. BMJ (Clinical research ed). 2012;345. http://dx.doi.org/10.1136/bmj.e6828

7. National Institute for Health and Clinical Excellence. Increasing the uptake of HIV testing among black Africans in England. 2011 [cited 2014 02/02/14]; Available from: http://publications.nice.org.uk/increasing-the-uptake-of-hiv-testing-amongblack-africans-in-england-ph33.

8. National Institute for Health and Clinical Excellence. Tuberculosis: Clinical diagnosis and management of tuberculosis, and measures for its prevention and control. 2011; Available from: http://publications.nice.org.uk/tuberculosis-cg117.

9. Griffiths $C$, Sturdy P, Brewin P, et al. Educational outreach to promote screening for tuberculosis in primary care: a cluster randomised controlled trial. Lancet 2007;369(9572):1528-34. Epub 2007/05/08.

10. Brewin $P$, Jones $A$, Kelly $M$, et al. Is screening for tuberculosis acceptable to immigrants? A qualitative study. Journal of Public Health 2006;28(3):253-60. http://dx.doi.org/10.1093/pubmed/fdl031

11. Bothamley GH, Rowan JP, Griffiths CJ, et al. Screening for tuberculosis: the port of arrival scheme compared with screening in general practice and the homeless. Thorax 2002;57(1):45-9. Epub 2002/01/26.

12. Pareek $M$, Watson JP, Ormerod $L P$, et al. Screening of immigrants in the UK for imported latent tuberculosis: a multicentre cohort study and cost-effectiveness analysis. The Lancet infectious diseases 2011;11(6):435-44. http://dx.doi.org/10.1016/S1473-3099(11)70069-X

13. Leber $\mathrm{W}, \mathrm{McMullen} \mathrm{H}$, Martin $\mathrm{N}$, et al. Point-of-care HIV testing in primary care and early detection of HIV (RHIVA2): a cluster randomised controlled trial. 2013 [cited 2014 02/02/2014]; Available from: http://www.thelancet.com/journals/lancet/article/ PIIS0140-6736(13)62255-2/abstract.

14. World Health Organization (WHO). Global tuberculosis report 2013. World Health Organization; 2013; [Internet] Available from: http://www.who.int/tb/ publications/global_report/en/

15. Kompala T, Shenoi S V, Friedland G. Transmission of tuberculosis in resource-limited settings. Curr. HIVIAIDS Rep 2013;10(3):264-72. http://dx.doi.org/10.1007/s11904-013-0164-x

16. Cegielski JP, McMurray DN. The relationship between malnutrition and tuberculosis: evidence from studies in humans and experimental animals. Int J Tuberc Lung Dis 2004;8(3):286-98

17. WHO. Definitions and reporting framework for tuberculosis - 2013 revision [Internet]. Available from: http://apps.who.int/iris/bitstream/10665/79199/1/ 9789241505345_eng.pdf

18. Steingart KR, Ramsay A, Dowdy DW, Pai M. Serological tests for the diagnosis of active tuberculosis: relevance for India. Indian J Med Res 2012;135:695-702

19. World Health Organization. Commercial serodiagnostic tests for diagnosis of tuberculosis: policy statement. WHO, Geneva. 2011; [Internet] Available from: http://whqlibdoc.who.int/publications/2011/9789241502054_eng.pdf

20. Sachdeva K S, Management of Tuberculosis: Indian Guidelines. Available at: www.apiindia.org/medicine_update_2013/chap105.pdf?

21. Steingart KR, Ramsay A, Pai M. Optimizing sputum smear microscopy for the diagnosis of pulmonary tuberculosis. Expert Rev Anti Infect Ther 2007;5(3):327-31. http://dx.doi.org/10.1586/14787210.5.3.327

22. World Health Organization. Treatment of tuberculosis guidelines. 4th Edn. Document WHO/HTM/TB/2009.420. Geneva, World Health Organization,2010; [Internet] Available from: http://www.who.int/tb/publications/2010/ 9789241547833/en/

23. Morse M, Kessler J, Albrecht S, et al. Induced sputum improves the diagnosis of pulmonary tuberculosis in hospitalized patients in Gaborone, Botswana. Int J Tuberc Lung Dis 2008;12(11):1279-85.

24. Chang KC, Leung CC, Yew WW, Tam CM. Supervised and induced sputum among patients with smear-negative pulmonary tuberculosis. Eur Respir J 2008;31(5): 1085-90. http://dx.doi.org/10.1183/09031936.00122907

25. Tuberculosis Coalition for Technical Assistance. International Standards for Tuberculosis Care (ISTC). The Hague: Tuberculosis Coalition for Technical Assistance, 2006. [Internet]. Available from: http://www.who.int/tb/publications/ 2006/istc_report.pdf

26. Parsons LM, Somoskövi A, Gutierrez C, et al. Laboratory diagnosis of tuberculosis in resource-poor countries: challenges and opportunities. Clin Microbiol Rev 2011; 24(2):314-50. http://dx.doi.org/10.1128/CMR.00059-10

27. Uddin MKM, Chowdhury MR, Ahmed S, et al. Comparison of direct versus concentrated smear microscopy in detection of pulmonary tuberculosis [Internet].
BMC Res. Notes. 2013. p. 291. Available from: http://www.biomedcentral.com/ content/pdf/1756-0500-6-291.pdf http://dx.doi.org/10.1186/1756-0500-6-291

28. World Health Organization (WHO). Fluorescent light emitting diode (LED) microscopy for diagnosis of tuberculosis: policy statement. Geneva, World Health Organization,2010; [Internet]. Available from: http://whqlibdoc.who.int/publications/ 2011/9789241501613_eng.pdf

29. Getahun H, Kittikraisak W, Heilig CM, et al. Development of a standardized screening rule for tuberculosis in people living with HIV in resource-constrained settings: individual participant data meta-analysis of observational studies. PLoS Med 2011;8(1):e1000391. Available from: http://www.ncbi.nlm.nih.gov/pmc/ articles/PMC3022524/pdf/pmed.1000391.pdf http://dx.doi.org/10.1371/journal.pmed.1000391

30. Menzies D, Benedetti A, Paydar A, et al. Standardized Treatment of Active Tuberculosis in Patients with Previous Treatment and/or with Mono-resistance to Isoniazid: A Systematic Review and Meta-analysis. Murray M, editor. PLoS Med 2009;6(9):e1000150. Available from: http://www.ncbi.nlm.nih.gov/pmc/articles/ PMC2736385/pdf/pmed.1000146.pdf

31. Chang KC, Leung CC, Grosset J, Yew WW. Treatment of tuberculosis and optimal dosing schedules. Thorax 2011;66(11):997-1007. http://dx.doi.org/10.1136/thx.2010.148585

32. Gandhi MP, Kumar AMV, Toshniwal MN, et al. Sputum Smear Microscopy at Two Months into Continuation-Phase: Should It Be Done in All Patients with Sputum Smear-Positive Tuberculosis? PLoS One 2012;7(6):e39296. Available from: http://www.ncbi.nlm.nih.gov/pmc/articles/PMC3378531/pdf/pone.0039296.pdf http://dx.doi.org/10.1371/journal.pone.0039296

33. World Health Organization. Guidelines for the programmatic management of drugresistant tuberculosis, 2011 update. Geneva, WHO, 2011. [Internet] Available from:http://whqlibdoc.who.int/publications/2011/9789241501583_eng.pdf.

34. Caminero JA, ed. Guidelines for Clinical and Operational Management of DrugResistant Tuberculosis. Paris, France: International Union Against Tuberculosis and Lung Disease, 2013. Available from: http://www.theunion.org/what-wedo/publications/technical/english/mdr-tbguide_6-19-13_web.pdf

35. Lopes T, Gomes C, Diogo N. Tuberculosis unit: case study of 10 years of activity (1999-2009). Rev Port Pneumol 2011;17:266-71

http://dx.doi.org/10.1016/j.rppneu.2011.06.008

36. Mnyani CN, McIntyre JA. Tuberculosis in Pregnancy. BJOG 2011;118:226-31.

37. Hershko C, Nesher G, Yinnon AM, et al. Medical problems in Ethiopian refugees airlifted to Israel: experience in 131 patients admitted to a general hospital. J Trop Med Hyg 1986;89:107-12.

38. Nahmias J, Greenberg Z, Berger SA, et al. Health profile of Ethiopian immigrants in Israel: an overview. Isr J Med Sci 1993;29(6-7):338-43.

39 Arieli A, Aycheh S. Psychopathology in Ethiopian Jewish immigrants. Harefuah 1991;121:417-21.

40. Kleinman A, Benson P. Anthropology in the clinic: the problem of cultural competency and how to fix it. PLoS Med 2006;3:e294. http://dx.doi.org/10.1371/journal.pmed.0030294

41. Johnson G, Helman C. Remedy or cure? Lay beliefs about over-the-counter medicines for coughs and colds. Br J Gen Pract 2004;54:98-102.

42. Kan B, Kalin M, Bruchfeld J. Completing treatment for latent tuberculosis: patient background matters. Int J Tuberc Lung Dis 2013;17:597-602. http://dx.doi.org/10.5588/ijtld.12.0692

43. Stewart M. Towards a global definition of patient centred care. BMJ 2001;322:4445. http://dx.doi.org/10.1136/bmj.322.7284.444

44. Rosen H. Ethiopian Jews: an historical sketch. Isr J Med Sci 1991;27:242-3.

45. Yaphe J, Schein M, Naveh P. Ethiopian parents' perception of their children's health: A focus group study of immigrants to Israel. IMAJ 2001;3:932-6.

46. Tandeter H, Grynbaum M, Borkan J. A qualitative study on cultural bloodletting among Ethiopian immigrants. Isr Med Assoc J 2001;3:937-9.

47. Mor Z, Lerman $Y$, Leventhal A. Pre-immigration screening process and pulmonary tuberculosis among Ethiopian migrants in Israel. Eur Respir J 2008;32:413-18. http://dx.doi.org/10.1183/09031936.00145907

Commissioned article; externally peer-reviewed; received 2 nd January 2014; accepted 11th February 2014; online 28th February 2014

(C) 2014 Primary Care Respiratory Society UK. All rights reserved.

C Griffiths et al. Prim Care Respir J 2014;23(1):106-111

http://dx.doi.org/10.4104/pcrj.2014.00019 